\title{
Health research on the Irish in Britain: invisible and excluded
}

\author{
Gerard Leavey, Grania Clarke, Michael King and Roland Littlewood
}

London's Mental Health: The Report to the King's Fund London Commission has been launched (Johnson et al, 1997). This is a large and detailed report which pulls together the best available data and research taken from a wide variety of sources to provide a panoramic view of mental health services in London. There is valuable information here that ought to have considerable impact for future provision of services. The mental health of London's ethnic minorities is clearly an important topic and one that is given a justifiably prominent profile throughout.

In keeping with past reviews and discussion documents on ethnicity and health there is no reference to the Irish community in any of the 400 pages. What should we draw from this omission? Is it that the Irish population in London is too small to merit discussion or that the research evidence reveals an Irish community devoid of poor health, physical or mental? Both explanations are untrue. The Irish community is the largest ethnic community by migration in 23 of the 32 London boroughs and in 12 boroughs the Irish-born alone form the largest minority ethnic group. Boroughs with the highest populations of Irish people are mainly in inner areas of west and north-west London (Walter, 1991). On various indices of material deprivation they share a profile similar to that of other minority ethnic groups (Owen, 1995). Several recent studies on ethnicity and health show very high mortality rates for Irish people living in Britain compared to the general population and in comparison with other ethnic groups (Balarajan, 1996). Mortality among the second generation Irish is significantly higher than overall mortality for all causes and most major causes of death (Harding \& Balarajan, 1996).

Irish-born people in England and Wales have the highest admission rates to psychiatric hospitals for most major diagnoses (except schizophrenia) of any ethnic group (Cochrane \& Bal, 1989). A recent study in north London gave similar results (Walls, 1996). High rates of suicide and attempted suicide among Irish people living in Britain have been documented over three decades (Burke, 1976; Merril \& Owens, 1988). Mortality data classified by country of birth (census data 1988-1992) show the Irish in England and Wales to have a rate of 17.4 deaths from suicide and unexplained death per 100000 , an excess of $53 \%$ (Raleigh \& Balarajan, 1992). Suicide rates of migrant groups tend to reflect the pattern found in their home country and migration therefore does not generally increase the risk of suicide. For Irish migrants this does not appear to be the case.

These findings demonstrate quite clearly that the mental (and physical) health of the Irish must be considered as a high priority within our health service. Dedicated research is needed to address the high levels of psychological distress within the Irish community in Britain. Despite the evidence, and for reasons unclear to us, this group remain invisible at the 'why' end of the research spectrum. If the reasons for exclusion lie within the definition of ethnicity and race then we need to know this and debate it. Likewise if the exclusion has a political dimension. Whichever subgroup of the general population the Irish are placed within there is surely no justification for their exclusion from this report which is directed at policy influence and will have research and resource implications. Interestingly, the authors of the report suggest that a new research agenda is needed "which is part of a coordinated strategy to address the many important gaps in our current knowledge. For example, the Chinese and Vietnamese communities have received far less funding or research than other communities" (p. 157). The Irish are a large migrant group who form a significant proportion of the population in London. We wonder why they remain the invisible ethnic minority.

\section{References}

BALARAJAN, R. (1996) Ethnicity and variations in the nations health. Health Trends, 27, 114-119.

BURKE, A. W. (1976) Attempted suicide among Irish-born population in Birmingham. British Joumal of Psychiatry, 128, 534-537.

COCHRANE, R. \& BAL, S. S. (1989) Mental hospital admission rates of immigrants to England: a comparison of 1971 and 1981. Social Psychiatry and Psychiatric Epidemiology, 24, 2-11. 
HARDING, S. \& BALARAJAN, R. (1996) Patterns of mortality in second generation Irish living in England and Wales: longitudinal study. British Medical Journal, 312,1389 1392.

JohnSON, S., RAMSAY, R., ThORNICROFT, G., et al (eds) (1997) London's Mental Health: The Report to the King's Fund London Commission. London: King's Fund.

MERRIL, J. \& OWENS, J. (1988) Self-poisoning among four immigrant groups. Acta Psychiatrica Scandinavica, 77. 77-80.

OWEN, D. (1995) Irish-born people in Great Britain: Settlement patterns and socio-economic circumstances. 1991 Census Statistical Paper No. 9. Coventry: Centre for Research in Ethnic Relations, University of Warwick.

RALEIGH, V. S. \& BALARAJAN. R. (1992) Suicide levels and trends among immigrants in England and Wales. Health Trends, 24, 91-94.

WALLS, P. (1996) Researching Irish Mental Health: Issues and evidence, a study of the mental health of the Irish community in Haringey. London: Muintearas.
WALTER. B. (1991) Census 1991: Irish in London. Census Briefing for Action Group for Irish Youth. London: Action Group for Irish Youth.

*Gerard Leavey, Research Coordinator, Haringey Healthcare NHS Trust, Kate Marsden Unit, St Ann's Hospital, St Ann's Road, London N15 3TH; Grania Clarke, Director Health Concern For Irish People; Michael King, University Department of Psychiatry, Royal Free Hospital, London; and Roland Littlewood, Professor of Psychiatry. University College London

\section{*Correspondence}

\section{(-) \\ Seminars in the Psychiatry of Learning Disabilities}

\section{Edited by Oliver Russell}

This volume is both an up to date account of recent advances in the field of learning disabilities and a practical guide to the diagnosis and treatment of psychiatric disorder. Chapters on the classification of psychiatric disorders in people with learning disabilities, the epidemiology of intellectual disability and the diagnosis of psychiatric disorder are followed by more detailed accounts of autism, behavioural phenotypes and communication disorders. Psychiatric disorders are covered in the latter part of the book, including discussions on behavioural interventions, counselling and epilepsy. The book concludes with a review of forensic aspects of psychiatric management and treatment. 1997, 288pp, ISBN $0901242021, £ 15.00$

The College Seminars Series and other Gaskell publications are available from Booksales,

Publications Department, Royal College of Psychiatrists, 17 Belgrave Square, London

SW1X 8PG (Tel. +44(0)171 235 2351, extension 146). The latest information on College publications is available on the INTERNET at: http://www.demon.co.uk/rcpsych/ 